\title{
REFLEXÕES SOBRE A LATERAL POSVOCÁLICA NA FALA DA COMUNIDADE DE SANTO ANTONIO DE LISBOA ${ }^{1}$
}

\author{
REFLECTIONS ON LATERAL CODA ON SANTO ANTONIO DE LISBOA \\ COMMUNITY SPEAKING
}

\author{
Lílian Elisa Minikel Brod ${ }^{2}$ \\ Doutoranda do Programa de Pós-graduação em Linguística - UFSC
}

\begin{abstract}
Resumo
Resultados de pesquisas sociolinguísticas acerca do segmento lateral posvocálico no português do Brasil têm elucidado um fenômeno em variação. De acordo com esses estudos, a mudança linguística, categórica em algumas regiões, se apresenta em um estágio menos avançado em outras. O objetivo deste trabalho foi investigar 0 comportamento do segmento lateral posvocálico na comunidade de Santo Antônio de Lisboa, Florianópolis, SC. Os dados foram coletados de entrevistas realizadas com oito informantes dessa comunidade. Os resultados obtidos indicam mudança linguística em progresso.
\end{abstract}

Palavras-chave: Sociolinguística. Lateral posvocálica. Variação.

\begin{abstract}
Sociolinguistics studies about Brazilian Portuguese lateral coda had demonstrated a variation phenomenon. According to these studies, language changing has been less advanced in some regions than others. The aim of this work was to investigate lateral changing in coda in Santo Antonio de Lisboa, Florianopolis, SC. Data were collected from interviews carried out with eight speakers from this community. Results indicated linguistic changing in progress.
\end{abstract}

Key-words: Sociolinguistics. Lateral coda. Variation.

\section{INTRODUÇÃO}

Estudos acerca do segmento lateral posvocálico no português do Brasil (doravante PB) têm revelado uma mudança em curso que, para alguns dialetos, atinge seu estágio avançado: a vocalização do segmento. Esses resultados indicam um fenômeno em variação que, não totalmente implementado, se manifesta num contínuo com características de transição que divergem entre as regiões. O objetivo deste estudo foi investigar o comportamento do segmento lateral posvocálico na fala de informantes da comunidade de Santo Antonio de Lisboa, Florianópolis/SC. Para cumprir com esse objetivo, elegemos questões norteadoras para avaliar as motivações sociais e estruturais e, para tal, formulamos questões e esboçamos algumas hipóteses amparadas na literatura, que descrevemos a seguir:

\footnotetext{
${ }^{1}$ Estudo realizado como requisito parcial à disciplina Sociolinguística do Programa de Pós Graduação em Linguística - UFSC, sob a orientação da Prof. Dra. Izete Lehmkuhl Coelho.

${ }^{2}$ Doutoranda do Programa de Pós Graduação em Linguística - UFSC.
} 
(i) Quais as variantes do segmento lateral posvocálico presentes no falar desta comunidade? A literatura apresenta a vocalização do segmento lateral como um fenômeno categórico para o PB. No entanto, estudos recentes têm registrado um fenômeno em variação em muitas regiões do Brasil, motivado interna e externamente por fatores que, ora estão em consonância, ora divergem (LEITE, CALLOU e MORAES, 2003). Reconhecendo a necessidade de olhar com acuidade para este objeto, nossa hipótese sustenta que o falar da comunidade de Santo Antonio de Lisboa apresenta um fenômeno em variação em razão, entre outros condicionadores, de sua herança açoriana.

(ii) Que variáveis internas interferem na ocorrência de uma determinada variante do segmento lateral em coda silábica? Postulamos a influência dos contextos anterior e seguinte no comportamento variável, especialmente, os contextos vogal baixa [a] e segmentos plosivos como favorecedores à vocalização da lateral posvocálica (LEITE, CALLOUe MORAES, 2003).

(iii) Em relação às variáveis externas, idade e escolaridade favorecem o uso de uma das variantes do fenômeno investigado? A literatura tem reportado uma tendência à vocalização entre os falantes mais jovens, e nossa hipótese segue a mesma linha (LEITE, CALLOU e MORAES, 2003).

Esta investigação insere-se no campo da pesquisa sociolinguística de perspectiva laboviana que, atenta à variação inerente ao sistema, pretende, no estudo empírico, determinar as condições para a mudança. Inicialmente, na Seção 1.2, nos reportamos aos estudos de Leite, Callou e Moraes (2003), que apresentam dados sobre a vocalização da lateral posvocálica, e apresentamos os estudos realizados por Espiga (2002; 2003), que registram a variação do segmento lateral em posição de coda nos dialetos de contato do português e espanhol, para caracterizar o fenômeno em estudo. $\mathrm{Na}$ Seção 2, são relatadas as características sociais e culturais que compõem a comunidade de Santo Antonio de Lisboa. Ainda nessa seção, são apresentados os aspectos concernentes à metodologia desta investigação. Os resultados são descritos e discutidos na Seção 3.

\subsection{A variação do segmento lateral}

No português do Brasil, os processos de ditongação ocorrem em diferentes contextos pela inserção de uma semivogal ou pela modificação de uma consoante em posição de coda silábica. Tradicionalmente os ditongos são classificados em relação à posição da vogal assilábica: (a) posposição da vogal assilábica à vogal silábica; e (b) vogal assilábica à esquerda do núcleo silábico. A fonologia não linear, por sua vez, reconhece igualmente dois grupos de ditongos: (a) pesado, associado a duas posições no esqueleto; e (b) leve, associado a uma posição.

Leite, Callou e Moraes (2003) investigaram o ditongo em sílaba travada por lateral, como por exemplo, em volta - vo[w]ta e mel - me[w] com base em dados de entrevistas extraídas do Projeto de Estudo da Norma Linguística Urbana Culta (Projeto NURC/Brasil), referentes às cidades do Rio de Janeiro, São Paulo, Porto Alegre, 
Salvador e Recife. A análise dos dados mostrou o processo de vocalização em posição interna e final em estágio avançado para o Rio de Janeiro (90\%), mas neutro para Porto Alegre (54\%). Em Salvador, a vocalização se mostra menos avançada em posição interna (72\%). Para os autores, a vocalização é um processo histórico registrado no latim, por volta dos séculos VI e VII, e reconhecido na evolução de outras línguas românicas, como o francês (XII), o italiano e o espanhol (IX). A primeira ocorrência desse ditongo registrada na língua portuguesa data do século XVIII, no Auto da partilha: "outros perdamentos”.

Além dos aspectos históricos reportados, fatores estruturais e sociais estariam condicionando os usos do fenômeno em variação. Em relação ao primeiro, vogal precedente e consoante seguinte determinaram a ocorrência da vocalização da lateral que, nos resultados dos autores, se manifestou com maior freqüência após uma vogal baixa em posição final e antes de consoante velar em posição interna. A análise dos fatores sociais - entre eles, faixa etária, gênero e região - revelou mudança em progresso para homens e mulheres em Salvador, mas estabilidade para mulheres e mudança em progresso para homens em Porto Alegre. Segundo os autores, esses dados confirmam a relevância do fator gênero para a análise deste fenômeno, pois comportamentos distintos foram observados entre homens e mulheres.

Leite, Callou e Moraes (2003) reiteram que o processo de vocalização encontra-se em estágio final nas regiões analisadas, exceto Porto Alegre. As etapas de mudança da variante alveolar [1] para a velar [ ] e, consequentemente, para a semivogal [w ] atestam a adição de uma articulação dorsal à consoante coronal para a primeira etapa, e posterior cancelamento do traço coronal na última etapa da transição.

A variação do segmento lateral posvocálico também foi objeto de investigação nos dialetos fronteiriços dos Campos Neutrais, nas comunidades de Chuí, fronteira Brasil e Uruguai, e Santa Vitória do Palmar. Espiga (2002; 2003) estudou a regra telescópica da lateral posvocálica em dialetos brasileiros como influência do contato com o espanhol. Para o autor, a variação observada nos dialetos de contato entre o português e o espanhol é resultado, em maior ou menor grau, do contato dessas línguas em cada comunidade, uma vez que o contínuo do português de fronteira apresenta características de transição entre o português do Brasil e o espanhol do Uruguai, sendo estes os pólos do contínuo linguístico português - espanhol.

De acordo com a pesquisa de Espiga (2002), todos os estágios da regra telescópica foram confirmados na região, com a inserção de uma posição intermediária entre o segundo e terceiro estágios da regra, isto é, entre o alofone velarizado [ ] e a semivogal [w]. A presença de um alofone coronal velarizado e labializado [ ${ }^{\mathrm{w}}{ }^{\mathrm{w}}$ no sistema foi verificada nos dialetos chuiense e vitoriense. Os resultados atestaram o predomínio da variante [1] no Chuí e da variante inovadora [ ${ }^{\text {w }}$ ] em Santa Vitória do Palmar. De acordo com o autor, os dados evidenciam uma tensão entre os pólos português e espanhol uma vez que o alofone $\left[1^{\mathrm{w}}\right]$ representa um fenômeno de mudança linguística própria do português do Brasil, em oposição ao alofone [1], cuja marca de preservação é própria do espanhol (ESPIGA, 2002). 
Com base nos dados referentes aos dialetos chuiense e vitoriense, Espiga (2002) observou uma gradação fonética do segmento lateral nessas regiões. A análise dos dados mostrou que algumas formas velarizadas apresentaram oclusão enfraquecida enquanto outras, maior retração e concavidade do dorso da língua; e, para as formas labializadas, variação no grau de arredondamento. Tal variação em relação à qualidade articulatória da lateral determinou critérios de distinção mínima para a identificação adequada do fonema. Essa classificação não contemplou formas híbridas ${ }^{3}$ que, segundo o autor, apresentaram simultaneamente os três gestos articulatórios - coronal, dorsal e labial. Espiga sugere uma categoria intermediária uma vez que essas formas não poderiam ser categorizadas como velar, pois apresentaram arredondamento dos lábios, tampouco como semivogal, pois mostraram indícios de coronalidade:

$$
/ 1 / \rightarrow[1] \sim[\quad] \sim\left[1^{\mathrm{w}}\right] \sim[\mathrm{w}] \sim \varnothing
$$

O alofone $\left[\mathrm{I}^{\mathrm{w}}\right]$ apresenta um caráter intermediário distinguindo-se da velar e da semivogal pela presença do gesto labial e coronal, respectivamente. A análise acústica dos dados também diferenciou as articulações secundárias dos alofones de /1/, confirmando o escopo da variação e a classificação proposta.

Para Espiga (2003), a variação da lateral posvocálica é uma mudança linguística interna orientada por variáveis sociais. Inicialmente, essa mudança denuncia a existência da regra telescópica em que os estágios do seu percurso diacrônico têm sido observados e tratados como variantes em alguns dialetos. Sendo assim, o alofone intermediário [ $1^{\text {w }}$ ], observado na variação da lateral posvocálica ente os alofones [ ] e [w], é um estágio transicional da regra telescópica entre [ ], do qual deriva, e [w] para o qual evolui. Essa transição também mostra o desdobramento do processo de vocalização para a labialização e vocalização, em que o primeiro implica a adição de apenas uma articulação secundária - o traço de ponto [labial]; e o segundo, a perda da articulação primária, ou seja, o desligamento do traço [coronal], permitindo que o som adquira qualidade vocálica. Por outro lado, segundo o autor, a preservação de [1] co-ocorre com os estágios da velarização [1] [ ] e labialização [ ] [ ${ }^{\text {w }}$ ]. Isso significa que as variantes encontradas na região coexistem com a tendência preservadora, indicando uma resistência à mudança efetiva.

A mudança em curso observada na região dos Campos Neutrais é orientada pelas variáveis sociais 'faixa etária' e 'escolaridade', cujos dados referentes ao Chuí e Santa Vitória do Palmar revelam, respectivamente, a preservação de [1] entre a população com idade acima de 50 anos (73\%); e baixa frequência de [1] na faixa etária de 26 a 50 anos (55\%) e de 16 a 25 anos (24\%). Esses resultados confirmam um comportamento linguístico inovador entre a população mais jovem (ESPIGA, 2002).

Em relação à variável 'escolaridade', os resultados indicaram um comportamento resistente à mudança na comunidade chuiense mais escolarizada, preservando o alofone [1] (57\%), enquanto os vitorienses mais escolarizados valorizaram a variante

\footnotetext{
3 Termo utilizado pelo autor para nomear sons que apresentam concomitantemente todas as características.
} 
[ 1 ] (57\%). Esses dados indicam uma tendência à supressão da variante posvocálica e a consequente implementação da variante inovadora no sistema. Essa mudança encontra espaço nos grupos sociais intermediários, motivada por fatores sociais (ESPIGA, 2002).

\section{METODOLOGIA}

Com base na observação da língua em seu contexto social e real de uso, o postulado teórico da teoria laboviana sustenta o princípio da heterogeneidade inerente ao sistema. Essa variação, que se revela nas formas próprias de falar de uma comunidade, é motivada linguística e socialmente (LABOV, 2008 [1972]).

As mudanças linguísticas são, então, condicionadas pelas forças internas, estruturais que atuam no sistema nos níveis sintático, fonológico, morfológico, semântico discursivo ou lexical. Os fatores externos ou condicionadores sociais que favorecem a mudança referem-se ao falante e a sua relação com a comunidade - gênero, faixa etária, escolaridade, estilo, nível socioeconômico, local, etc. A interação de tais fatores, linguísticos e sociais, pode explicar as mudanças linguísticas.

Para esta pesquisa que teve como objetivo investigar o comportamento do segmento lateral posvocálico na fala de oito (08) informantes da comunidade de Santo Antônio de Lisboa, Florianópolis/SC, falantes nativos do PB, buscamos respaldo nos pressupostos de Labov (2008 [1972]). Para cumprir com o objetivo deste estudo, foi realizado um mapeamento histórico-cultural da comunidade de Santo Antonio de Lisboa. Os dados foram coletados em amostras de fala semi-espontânea extraídas de entrevistas previamente planejadas e realizadas em sessões individuais com informantes cuidadosamente selecionados com o intuito de controlar possíveis variáveis. As variáveis linguísticas e sociais foram consideradas com a finalidade de averiguar fatores condicionadores do comportamento do segmento lateral nesta posição.

\subsection{A freguesia de Santo Antonio de Lisboa}

Santo Antônio de Lisboa, localizada na região noroeste da Ilha de Santa Catarina (Florianópolis), se organizou a partir de duas ruas principais paralelas ao mar. A costa litorânea circunscreve uma região que manifesta na cultura, na gastronomia, na arquitetura e na história, a herança portuguesa e, porque não dizer, a identidade dessa comunidade ${ }^{4}$. As primeiras observações atestam que, em meados do século XVIII, a economia da freguesia se fortalecia com o cultivo de cana-de-açúcar, mandioca, trigo, milho, café, hortaliças, e a produção de aguardente, açúcar, melado, farinha, cevada. A produção de farinha é memória recente na comunidade e a tradição se faz presente no Engenho de Farinha da família Andrade, como reporta o informante:

Meu marido hoje tá farinhando. Isso que dize que a gente comi a farinha que a gente própio faz, entendeu (...) $(\mathrm{H})^{5}$

\footnotetext{
${ }^{4}$ Esse texto é resultado de um mapeamento histórico-cultural acerca da comunidade de Santo Antônio de Lisboa e reúne excertos extraídos das entrevistas coletadas que atestam as opiniões e impressões do morador desta comunidade.

${ }^{5}$ A identidade dos informantes foi preservada.
} 
Embora a geografia da região não tenha promovido a atividade agrícola em maior escala, a diversidade de produtos favorecia a sustentabilidade das famílias que utilizavam o porto para o escoamento da produção agrícola e pesqueira. O porto foi decisivo para a abertura de casas comerciais que negociavam as mercadorias, produzidas também no norte da ilha e escoadas para o entreposto. O declínio da economia de Santo Antônio de Lisboa ocorre no início do século XX quando novas opções de transportes são oferecidas aos moradores, desfavorecendo a atividade portuária:

Ele me levava de carroça com ele. Daqui, daqui da Ponta do Sambaqui ou da Vargem, porque a gente já morô lá também, até o centro de carroça, mas antigamente não havia carro, então era muito tranqüilo (...) (H)

Essa situação é extenuada com a construção da estrada geral interligando o norte da ilha e o centro de Florianópolis, viabilizando o surgimento do transporte coletivo e enfraquecendo o transporte marítimo. Martinello (1997) reporta o surgimento da primeira linha de ônibus interligando a comunidade de Canasvieiras ao centro, passando por Santo Antonio de Lisboa, em meados de 1945, conforme atesta o informante:

Acompanhei a construção da SC 401 (...) Tinha um caminho que era uma estrada de areia muito ruim e eu me lembro da construção, tinha uns cinco anos quando ficô pronta a SC. (D)

Em seguida, o transporte coletivo intensifica os horários para atender a necessidade da população que, a partir daí, busca o mercado de trabalho central. Essa mudança também afeta o comportamento da comunidade que busca se estabelecer em lugares próximos ao trabalho:

Quando eu era criança, o ônibus ia de manhã, às 7 da manhã e voltava às 4 da tarde. Ninguém podia trabalhar no centro e morar aqui na década de 70. Aí depois começou a ter ônibus, isso antes do asfalto né. Quando começa a ter o asfalto, então daqui a pouco começa a ter ônibus ao meio dia, começa a ter um ônibus que sai de lá ao meio dia e um que sai daqui a 1 da tarde (...). E é nos anos 80, final dos 70 que as pessoas começam a trabalhar e morar aqui.

A maioria dos pescadores vendeu a sua terra e foi morar no morro. Então, é a cidade se colocando entre o pescadô e o mar. (D)

Dado relevante foi observado com relação à genealogia das famílias de ascendência portuguesa cuja transmissão de sobrenome se revela uma questão de classe e não de gênero. Segundo Ferreira (2005), homens e mulheres abandonavam seus sobrenomes assumindo nomes próprios de forma que sua origem humilde não se tornasse pública. Em relação às famílias abastadas, o sobrenome duplo perpetuava-se por mais de dois séculos indicando a família proprietária de grandes extensões de terras. Por essa razão, o autor reporta vários casos na freguesia de Santo Antonio de Lisboa de pessoas que assumiram o sobrenome paterno e materno, respectivamente, conforme o grau de importância econômica e social. 
Santo Antônio de Lisboa preserva sua identidade na herança cultural que se manifesta na realização da Festa do Divino, no folclore presente nas brincadeiras como boi-demamão, pau-de-fita e terno-de-reis:

Aí a gente faz a festa do Divino Espírito Santo e todos os meus filhos participam, meus netos. Devo até ter foto. E, e, e a gente que cuida, que organiza a igreja (...). (H)

O trabalho artesanal de renda de bilros e a pesca também assumem valor de referência para o açoriano que, nesse movimento de resgate, relembra o trabalho de gerações e integra a comunidade de Santo Antônio de Lisboa:

Que os meus bilros, que não estão aqui, eles são da minha tataravó, que já passou pela minha bisavó, pela minha vó, pela minha mãe (...). Eu sou a quinta geração, entendeu. Então eu sou a continuação deles, eles fizeram que eu continuasse a história. Assim como eu tenho uma neta que vai continuar a minha (...).

Somos a família toda pescador. Eu, a minha irmã. Aquela minha irmã que tá ali perto, ela abre a tarrafa mais do que um home. Enormes tarrafas, não são tarrafinha, ela abre toda. A família toda pescado (...). E a família intera saiu assim pescadô. Sabe mar, sabe praia, e a gente vive assim de pexi, da pesca, das ostras, camarão, meu marido pesca um monte. Minha família toda, minhas irmãs, quer dizer, gosta (...). (H)

A comunidade de Santo Antônio de Lisboa tem 6.934 habitantes, 3.426 homens e 3.508 mulheres. Sua área é estimada em $22,45 \mathrm{~km}^{2}$ e integra o Distrito de Santo Antônio de Lisboa juntamente com as comunidades de Cacupé, Sambaqui e Barra do Sambaqui.

\subsection{Participantes}

Um grupo de oito (08) informantes descendentes de portugueses, nascidos e residentes na comunidade de Santo Antônio de Lisboa, Florianópolis/SC, falantes nativos do PB, participou deste estudo. Quatro (04) informantes com idade abaixo de 50 anos, sendo dois (02) informantes com escolaridade fundamental e dois (02) informantes com escolaridade superior; e quatro (04) informantes com idade acima de 50 anos, sendo dois (02) informantes com escolaridade fundamental e dois (02) informantes com escolaridade superior. Para cada informante, amostras de fala espontânea foram coletadas.

\subsection{Coleta de dados}

Os dados foram coletados em entrevistas realizadas em sessões individuais no ambiente de trabalho, casa ou instituição de ensino do informante. As amostras de fala espontânea foram coletadas utilizando um gravador digital de voz e armazenadas em formato digital.

Com o objetivo de orientar o pesquisador no direcionamento da entrevista, um roteiro de perguntas foi elaborado com base no mapeamento histórico-cultural da comunidade 
de Santo Antônio de Lisboa (ver Seção 2.1). Nesse roteiro, foram contemplados aspectos considerados relevantes para a vida do morador desta comunidade como, por exemplo, a sua relação com o mar e a pesca, as manifestações culturais fortemente arraigadas nesse espaço, a infância e as lembranças desse período, a família e suas relações, e a intensa atividade turística na região.

\subsection{Caracterização das variáveis}

Para estudar o comportamento do segmento lateral, as variantes velar ], alveolar ], semivogal ] e apagamento ø] do segmento nesta posição foram analisadas.

A delimitação das variáveis linguísticas pretende apurar os fatores internos que condicionam a realização de uma ou outra forma. Para tanto, as variáveis linguísticas 'contexto anterior', 'contexto seguinte', 'tonicidade' e 'posição do segmento lateral na palavra' foram selecionadas para avaliar a influência que o ambiente adjacente exerce na realização da lateral posvocálica. Em relação ao 'contexto anterior', as vogais baixa [a], média alta [e], média baixa [ $\varepsilon$ ] e alta [i] anteriores; média alta [o], média baixa [o] e alta [u] posteriores foram consideradas. Para avaliar o efeito da variável 'contexto

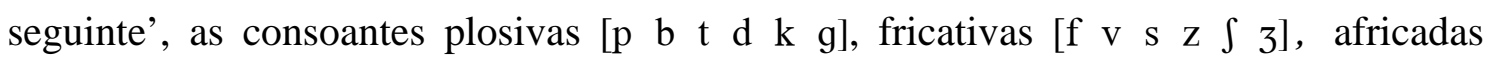
[ $\mathrm{t} \int \mathrm{d} 3$ ], nasais [m $\mathrm{n}$ ], pausa [\#] e as vogais [a e $\varepsilon$ i variáveis 'tonicidade' e 'posição do segmento lateral na palavra' foram especificadas, respectivamente, como sílaba tônica (t) e átona (a), e posição interna (i) ou final (f).

As variáveis sociais ‘idade' e 'escolaridade' foram selecionadas no estudo de modo que a influência desses condicionadores no comportamento variável do segmento lateral posvocálico pudesse ser examinada. Para analisar os condicionadores sociais favorecedores de um determinado alofone, as variáveis sociais 'idade' e 'escolaridade' contemplaram a faixa etária abaixo de 50 anos (-) e acima de 50 anos (+), bem como escolaridade fundamental (1) e superior (2). Conforme Naro (2003), as mudanças linguísticas ocorrem de maneira gradual e a manutenção ou implementação de certas formas está relacionada à faixa etária do falante, mas também pode ser motivada por fatores como escolaridade e prestígio, ou ainda, por pressões sociais que se efetivam em cada período.

\subsection{Análise dos dados}

Após segmentação, os dados foram devidamente categorizados observando a variável dependente e as variáveis independentes linguísticas e sociais previamente delimitadas. A categorização dos dados seguiu metodologia proposta pela sociolinguística laboviana. Após categorizados os dados, o pacote estatístico Goldvarb 2001 foi utilizado para análise quantitativa. 


\section{DESCRIÇÃO E ANÁLISE DOS RESULTADOS}

Foram analisadas 331 ocorrências do segmento lateral posvocálico, para as quais foi averiguado o percentual de ocorrências das variantes: semivogal ], velar ], apagamento [ø], gradiente [?] e alveolar ] do segmento nesta posição (Tabela 1).

TABELA 1. Percentual de ocorrências das variantes do segmento lateral posvocálico

\begin{tabular}{l|c|c|c|c|c|c}
\hline \multirow{2}{*}{ Ocorrências } & \multicolumn{7}{c}{ Variantes } \\
\cline { 2 - 7 } & {$[\mathrm{w}]$} & {$[$ ] } & {$[\varnothing]$} & ? & [ ] ] & Total \\
\hline Número de ocorrências & 184 & 41 & 81 & 11 & 14 & 331 \\
\hline Percentual \% & 54 & 12 & 24 & 3 & 4 & 100 \\
\hline
\end{tabular}

Os resultados obtidos estão de acordo com os resultados apresentados por Leite, Callou e Moraes (2003) para a cidade de Porto Alegre, onde o processo de vocalização se mantém neutro (54\%). Por essa razão, ainda que seja significativo o percentual de vocalização do segmento (54\%), os índices de ocorrência para a variante velar (12\%) e a supressão do segmento posvocálico (24\%) indicam que a mudança encontra resistência. Diante disso, seria relevante considerar a descendência portuguesa dos informantes uma vez que a comunidade de Santo Antônio de Lisboa foi predominantemente colonizada por imigrantes açorianos, provenientes da Ilha dos Açores onde a variante velar é predominante para o português europeu (PE).

Em relação à variável gradiente, aqui especificada como [?], esta apresenta variações acústicas na sua produção que, de acordo com Silva e Medeiros (2007), varia dentro de um contínuo físico, caracterizando uma alofonia gradiente. Tais alofonias seriam resultado da organização temporal dos gestos e da coordenação entre eles, ou seja, os gestos responsáveis por tal evento podem se sobrepor temporalmente - um gesto pode iniciar durante a ativação de outro gesto ou dois gestos podem iniciar no mesmo instante. O resultado dessa sobreposição total ou parcial seria atestada acústica e articulatoriamente (ALBANO, 2001). Não é pretensão deste estudo examinar exaustivamente tais características, mas mostrar a variação da lateral posvocálica observada no falar da comunidade de Santo Antonio de Lisboa.

Dado o percentual de ocorrências de cada uma das variantes observadas nesta pesquisa, foram examinadas as variáveis linguísticas 'contexto anterior', 'contexto seguinte', ‘tonicidade’ e ‘posição do segmento na palavra’ (Tabela 2).

Esses dados corroboram os resultados reportados por Leite, Callou e Moraes (2003), ratificando a vogal baixa como ambiente fonético condicionador do processo de vocalização do segmento lateral (61\%). Para a variável 'contexto seguinte', o comportamento do segmento lateral posvocálico foi bastante expressivo diante de consoantes plosivas (55\%), nasais (62\%), fricativas (54\%) e pausa (54\%), uma vez que estas se mostraram favoráveis à vocalização do segmento. Dentre este grupo, consoantes plosivas e pausa também se mostraram favoráveis ao apagamento do segmento lateral e velarização, (30\%) e (23\%), respectivamente. 
TABELA 2. Percentual e total de ocorrências das variáveis internas para as variantes do segmento lateral

\begin{tabular}{|c|c|c|c|c|c|c|c|}
\hline \multicolumn{2}{|c|}{ Variáveis Internas } & Apl/Total & [w ] & [ ] & {$[\varnothing]$} & $?$ & [1] \\
\hline \multirow{7}{*}{$\begin{array}{l}\text { Contexto } \\
\text { Anterior }\end{array}$} & $\mathrm{a}$ & 220/331 & $61 \%$ & $17 \%$ & $12 \%$ & $3 \%$ & $5 \%$ \\
\hline & $\mathrm{u}$ & $36 / 331$ & $8 \%$ & $5 \%$ & $82 \%$ & $2 \%$ & $0 \%$ \\
\hline & $\mathrm{i}$ & $16 / 331$ & $93 \%$ & $0 \%$ & $6 \%$ & $0 \%$ & $0 \%$ \\
\hline & 0 & $25 / 331$ & $36 \%$ & $0 \%$ & $60 \%$ & $4 \%$ & $0 \%$ \\
\hline & e & $5 / 331$ & $40 \%$ & $0 \%$ & $0 \%$ & $20 \%$ & $40 \%$ \\
\hline & $\mathrm{E}$ & $16 / 331$ & $93 \%$ & $6 \%$ & $0 \%$ & $0 \%$ & $0 \%$ \\
\hline & $\mathrm{O}$ & $14 / 331$ & $35 \%$ & $0 \%$ & $64 \%$ & $0 \%$ & $0 \%$ \\
\hline \multirow{12}{*}{$\begin{array}{l}\text { Contexto } \\
\text { Seguinte }\end{array}$} & plosiva & $156 / 331$ & $55 \%$ & $10 \%$ & $30 \%$ & $1 \%$ & $1 \%$ \\
\hline & nasal & 40/331 & $62 \%$ & $12 \%$ & $20 \%$ & $2 \%$ & $2 \%$ \\
\hline & pausa & 46/331 & $54 \%$ & $23 \%$ & $10 \%$ & $6 \%$ & $4 \%$ \\
\hline & africada & 8/331 & $62 \%$ & $0 \%$ & $25 \%$ & $12 \%$ & $0 \%$ \\
\hline & $\mathrm{e}$ & $5 / 331$ & $40 \%$ & $0 \%$ & $40 \%$ & $0 \%$ & $20 \%$ \\
\hline & fricativa & $59 / 331$ & $54 \%$ & $13 \%$ & $27 \%$ & $5 \%$ & $0 \%$ \\
\hline & $\mathrm{i}$ & 3/331 & $33 \%$ & $0 \%$ & $0 \%$ & $0 \%$ & $66 \%$ \\
\hline & $\mathrm{a}$ & 9/331 & $66 \%$ & $0 \%$ & $0 \%$ & $0 \%$ & $33 \%$ \\
\hline & $\mathrm{E}$ & $1 / 331$ & $0 \%$ & $0 \%$ & $100 \%$ & $0 \%$ & $0 \%$ \\
\hline & 0 & 2/331 & $50 \%$ & $0 \%$ & $0 \%$ & $0 \%$ & $50 \%$ \\
\hline & $\mathrm{u}$ & $1 / 331$ & $0 \%$ & $0 \%$ & $0 \%$ & $0 \%$ & $100 \%$ \\
\hline & $\mathrm{O}$ & $1 / 331$ & $100 \%$ & $0 \%$ & $0 \%$ & $0 \%$ & $0 \%$ \\
\hline \multirow{2}{*}{ Tonicidade } & $\mathrm{a}$ & $114 / 331$ & $46 \%$ & $5 \%$ & $44 \%$ & $1 \%$ & $1 \%$ \\
\hline & $\mathrm{t}$ & 217/331 & $60 \%$ & $16 \%$ & $13 \%$ & $4 \%$ & $5 \%$ \\
\hline \multirow{2}{*}{$\begin{array}{c}\text { Posição na } \\
\text { palavra }\end{array}$} & $\mathrm{i}$ & $162 / 331$ & $49 \%$ & $8 \%$ & $38 \%$ & $3 \%$ & $0 \%$ \\
\hline & $\mathrm{f}$ & 169/331 & $61 \%$ & $15 \%$ & $10 \%$ & $3 \%$ & $8 \%$ \\
\hline
\end{tabular}

Na análise da variável 'tonicidade', os resultados evidenciaram maior incidência de vocalização em sílaba tônica (60\%) e o apagamento do segmento lateral em sílaba átona. Os resultados obtidos para análise da posição do segmento lateral na palavra indicaram que, em posição interna e final de palavra, a vocalização do segmento lateral foi predominante.

As variáveis sociais consideradas neste estudo contemplaram a escolaridade e a faixa etária dos informantes. Para a variável 'escolaridade', os dois grupos definidos - baixa escolaridade e escolaridade superior - apresentaram resultados equilibrados em relação à seleção da variante: a vocalização do segmento lateral posvocálico foi predominante para $57 \%$ das ocorrências entre os informantes de baixa escolaridade e 54\% das ocorrências entre os informantes com escolaridade superior. Em relação à variável 'faixa etária', os resultados para os informantes com idade abaixo de 50 anos e informantes com idade acima de 50 anos revelaram comportamento distinto: maior percentual de ocorrências para a vocalização da lateral foi observado no grupo mais jovem. 
TABELA 3. Percentual e total de ocorrências das variáveis externas para as variantes do segmento lateral

\begin{tabular}{c|l|r|c|c|c|c|c}
\hline \multicolumn{2}{c|}{ Variáveis Externas } & Apl/Total & {$[\mathrm{w}]$} & {$[\mathrm{]}$} & {$[\varnothing]$} & $?$ & {$[\mathrm{l}]$} \\
\hline \multirow{2}{*}{ Escolaridade } & Superior & $200 / 331$ & $54 \%$ & $11 \%$ & $27 \%$ & $1 \%$ & $5 \%$ \\
\cline { 2 - 8 } & Fundamental & $131 / 331$ & $57 \%$ & $13 \%$ & $19 \%$ & $6 \%$ & $3 \%$ \\
\hline \multirow{2}{*}{ Idade } & -50 & $155 / 331$ & $66 \%$ & $7 \%$ & $20 \%$ & $3 \%$ & $3 \%$ \\
\cline { 2 - 8 } & +50 & $176 / 331$ & $46 \%$ & $17 \%$ & $28 \%$ & $3 \%$ & $5 \%$ \\
\hline
\end{tabular}

Os resultados apresentados para a variável 'escolaridade' confirmam os resultados acima descritos para o percentual de ocorrência da variável dependente. O percentual de ocorrências da variante vocalizada, tanto para o grupo mais escolarizado como para o grupo menos escolarizado, indica um processo de mudança linguística que não está totalmente implementado por conta das forças internas e externas atuantes no sistema. Conforme Espiga (2003), o comportamento variável da lateral posvocálica é uma mudança linguística interna orientada por variáveis sociais.

Após a primeira análise das variantes, optou-se por realizar uma análise binomial das variantes semivogal e velar para as quais os resultados apontaram os grupos informante, tonicidade, contexto anterior e idade, nessa ordem, como variáveis significativas para esta análise (TABELA 4).

TABELA 4. Peso relativo da vocalização, percentual de ocorrências das variáveis consideradas significativas em relação à vocalização e velarização da lateral posvocálica

\begin{tabular}{|c|c|c|c|c|c|}
\hline \multicolumn{2}{|c|}{ Variáveis Internas } & Apl/Total & [w] & ] & Peso \\
\hline \multirow{7}{*}{$\begin{array}{l}\text { Contexto } \\
\text { Anterior }\end{array}$} & $\mathrm{a}$ & $173 / 229$ & $78 \%$ & $21 \%$ & 0,426 \\
\hline & $\mathrm{u}$ & $5 / 229$ & $60 \%$ & $40 \%$ & 0,143 \\
\hline & i & $16 / 229$ & $93 \%$ & $6 \%$ & 0,893 \\
\hline & 0 & $10 / 229$ & $90 \%$ & $10 \%$ & 0,498 \\
\hline & e & $3 / 229$ & $66 \%$ & $33 \%$ & 0,300 \\
\hline & $E$ & $16 / 229$ & $93 \%$ & $6 \%$ & 0,894 \\
\hline & $\mathrm{O}$ & $6 / 229$ & $83 \%$ & $16 \%$ & 0,304 \\
\hline \multirow{2}{*}{ Tonicidade } & $\mathrm{a}$ & $59 / 225$ & $89 \%$ & $10 \%$ & 0,749 \\
\hline & $\mathrm{t}$ & $166 / 225$ & $78 \%$ & $21 \%$ & 0,404 \\
\hline \multicolumn{2}{|c|}{ Variáveis Externas } & Apl/Total & {$[\mathrm{w}]$} & ] & $\begin{array}{c}\text { Peso } \\
\text { Relativo } \\
\end{array}$ \\
\hline \multirow{2}{*}{ Idade } & -50 & $114 / 225$ & $90 \%$ & $9 \%$ & 0,781 \\
\hline & +50 & $111 / 225$ & $72 \%$ & $27 \%$ & 0,213 \\
\hline \multirow{8}{*}{ Informante } & $\mathrm{A}$ & $58 / 226$ & $84 \%$ & $15 \%$ & 0,240 \\
\hline & B & $7 / 226$ & $85 \%$ & $14 \%$ & 0,213 \\
\hline & $\mathrm{C}$ & $34 / 226$ & $94 \%$ & $5 \%$ & 0,923 \\
\hline & $\mathrm{D}$ & $33 / 226$ & $66 \%$ & $33 \%$ & 0,468 \\
\hline & $\mathrm{E}$ & $24 / 226$ & $95 \%$ & $4 \%$ & 0,568 \\
\hline & $\mathrm{F}$ & $26 / 226$ & $96 \%$ & $3 \%$ & 0,606 \\
\hline & $\mathrm{G}$ & $8 / 226$ & $37 \%$ & $62 \%$ & 0,293 \\
\hline & $\mathrm{H}$ & $36 / 226$ & $66 \%$ & $33 \%$ & 0,397 \\
\hline
\end{tabular}


Para atender critérios de distinção mínima entre os alofones pesquisados, foram usadas análises acústicas dos dados na tentativa de investigação das características diferenciais. Foram observadas diferenças em relação à duração relativa dos segmentos, uma vez que, de acordo com Dalston (1974), em estudo realizado com adultos, há uma maior duração apresentada pela lateral em relação à semivogal [w], evidenciando que o alofone 'lateral velar' exige um movimento maior por conta do contato da língua com o outro articulador. Dessa forma, a língua manifestaria um “atraso” após o contato já que o som é produzido com um movimento maior, confirmando as diferenças de duração entre os alofones.

Reiteramos, no entanto, a necessidade de um tratamento acústico mais detalhado para os dados coletados, o qual será realizado em momento oportuno.

\section{CONCLUSÃO}

Os resultados obtidos nesse estudo parecem indicar uma mudança em progresso. Embora a variante velar e o apagamento do fonema sejam às vezes expressivos, a vocalização da lateral em coda é predominante. Na análise dos fatores externos, especialmente com relação à variável "idade”, a probabilidade da forma vocalizada na faixa etária abaixo de 50 anos parece indicar o predomínio dessa variante em detrimento de outras, enquanto na faixa de mais idade ocorre uma inversão. Ainda, na investigação das motivações linguísticas, os resultados corroboram as pesquisas confirmando a vogal baixa e a tonicidade como fatores condicionantes. No entanto, um estudo mais detalhado com base em um banco de dados mais extenso pode fornecer uma análise mais acurada do fenômeno.

\section{REFERÊNCIAS}

ALBANO, E. O gesto e suas bordas: esboço de fonologia acústico-articulatória do português brasileiro. Campinas (SP): Mercado das Letras, 2001.

CECA - Centro de Estudos Cultura e Cidadania. Uma cidade numa ilha: relatório sobre os problemas sócio-ambientais da Ilha de Santa Catarina. Florianópolis: Insular, 1996.

DALSTON, R. Acoustic characteristics of English /w,r,l/ spoken correctly by Young children and adults. Jasa, V.57, N.2, 1975.

ESPIGA, J. A lateral posvocálica na fronteira dos Campos Neutrais: estudo sociolingüístico da regra telescópica nos dialetos de Chuí e Santa Vitoria do Palmar. Letras de Hoje. Porto Alegre. v. 37, n. 1, p. 49-68, março, 2002.

ESPIGA, J. Alofonia de /L/ no sul do Rio Grande do Sul: aspectos fonéticos e fonológicos. In: HORA, D. COLLISCHONN, G. Teoria linguística: fonologia e outros temas. João Pessoa: Editora Universitária/UFPB, 2003.

FERREIRA, S. L. É possível uma abordagem histórica genealógica a partir dos dados da genealogia da história? Revista Esboços, Florianópolis, vol. 12, n. 13, 2005. 
LABOV, W. Padrões sociolingüísticos. São Paulo: Parábola Editora, 2008 [1972].

LEITE, Y., CALLOU, D., MORAES, J. Processos em curso no português do Brasil: a ditongação. In: HORA, D., COLLISCHONN, G. Teoria linguística: fonologia e outros temas. João Pessoa: Editora Universitária/UFPB, 2003.

MARTINELLO, D. M. A comunidade de Santo Antônio de Lisboa. Revista Katálisys, Florianópolis, n. 1, p. 31-31, 1997.

NARO, A. O dinamismo das línguas. In: MOLLICA, C., BRAGA, M. L. (orgs.). Introdução à Sociolinguística: o tratamento da variação. São Paulo: Contexto, 2003.

SILVA, A. H. P., MEDEIROS, B. R. Fonologia Articulatória: novas respostas para velhos problemas. In: Reis, C. (org.) Fonética e Fonologia: IX Congresso Nacional e III Internacional, 2007.Disponível em: http://www.letras.ufmg.br/labfon/congresso_2006/19-Fonologia_Articulatrianovas_respostas.pdf $>$. Acesso em: 08 outubro 2009. 